\title{
He Looks Six Years Younger in that Porsche: Do the Qualities of Products Transfer to Their Owners?
}

\author{
R. A. A. Raja Ahmad Effendi ${ }^{1,2} \&$ T. W. Allan Whitfield ${ }^{1}$ \\ ${ }^{1}$ Faculty of Design, Swinburne University of Technology, Melbourne, Australia \\ ${ }^{2}$ Faculty of Design \& Architecture, Universiti Putra Malaysia, Selangor Darul Ehsan, Malaysia \\ Correspondence: T. W. Allan Whitfield, Faculty of Design, Swinburne University of Technology, 144 High St \\ Prahran, Melbourne VIC 3181, Australia. Tel: 61-3-9214-6882. E-mail: awhitfield@swin.edu.au
}

Received: August 8, 2012 Accepted: September 7, 2012 Online Published: November 30, 2012

doi:10.5539/ass.v8n15p250

URL: http://dx.doi.org/10.5539/ass.v8n15p250

\begin{abstract}
Designed objects acquire and project various qualities through their appearance, materials, price, and advertising. This is clearly apparent in the automotive industry: a Ford 'communicates' a certain message about its product qualities, while a Porsche 'communicates' an entirely different message. Logic leads us to question whether designed objects - in this case cars - do in fact project a specific image or social position that is conferred upon their owners? A considerable body of literature positively answers the first question, yet the second has been neglected. The aim of the current research was to investigate if product qualities are transferred to product owners, by providing empirical evidence showing a shift in third-party perception of an owner when associated with a specific car model. Using a method derived from environmental psychology which demonstrates that the room a person inhabits affects perceptions of that person - the Room Effect - the present research sought to uncover whether the same effect could be demonstrated when associating a person with a product. An internet survey visually depicting (male/female, Asian/Caucasian) owners alongside their (Mercedes Benz/Proton) cars asked respondents to rate the owner on scales representing personality (the Five-Factor Model), physical attributes, and social attributes. Results demonstrated a Product Effect, though not as expected. The effect was most pronounced for the Caucasian male, with lesser effects for the Caucasian and Asian females, and none for the Asian male. The discussion draws on evolutionary and social psychology to provide a plausible explanation for the results.
\end{abstract}

Keywords: aesthetics, perception, psychology of design, research methods

\section{Introduction}

Popular culture, especially advertising, suggests that through association with the objects we own (Grubb \& Grathwohl, 1967), carry, or even talk about, we may reveal aspects of our personality and social position and hence affect how we are seen by others. In theory, a balding male in mid-life crisis who perceives himself to be young, powerful, or flashy supposedly trims years off his age and enhances his image behind the wheel of a Porsche.

People's personalities and social status are thus inferred from the way they dress and the products associated with them (Borkenau \& Libler, 1995; Montepare and Zeborowitz-McArthur, 1988; Laumann \& House, 1970). This was first articulated by Veblen (1899) in his now classic The Theory of the Leisure Class. The originator of the term conspicuous consumption, Veblen described the role of possessions in defining our social identity. In The Presentation of Self in Everyday Life, Goffman (1959) extended this social position attribution to one's setting. For example, the living-room becomes a stage on which people perform for their guests; with furnishings acting as props. Given the potential role of products and possessions in defining people, it is understandable that people will attend to such defining characteristics in the products that they acquire. It is further understandable that marketers will focus on these defining characteristics - as will designers who must deliver them.

This marketing position is encapsulated by Levy (1999: p 205): "People buy things not only for what they can do, but also for what they mean." Hence products possess not only utilitarian functions, but also symbolic meanings. People analyse these meanings in terms of their lifestyle and status, and seek congruence. This has been termed product-personality congruence, and influences purchase (Govers \& Shoormans, 2005). Yet products vary in the 
degree to which they are symbolic. According to Munson and Spivey (1980), conspicuous products such as cars are highly symbolic, while inconspicuous products such as tennis rackets are less symbolic. The symbolism is by no means facile: an electric car signifies environmental awareness, and its purchase cost indicates middle income; at the same time, its visual design characteristics display what has been termed product personality. Congruence must be weighted across these variable defining characteristics.

Product personality itself is a form of anthropomorphism: products display human or animal characteristics (Govers, 2004; Govers \& Schoormans, 2005) such as cute, friendly, modern, youthful, or traditional. Aaker (1999) contends that product personality derives from the notion of brand personality. Although both are wrapped in the same package, Govers and Mugge (2004) argue that product personality differs from brand personality in that the former refers to a specific product, which differs from a global brand. Product personality is conveyed through visual characteristics (Brunel \& Kumar, 2007; Kesteren, Stappers \& Khandachar, 2005). Consumers can discern these product personalities (Govers \& Mugge, 2004), and favour those congruent with their own or aspired self-image (Govers \& Schoormans, 2005).

A further symbolic meaning of products is the status they confer on their owner (Heffner, 2007). Tracing its lineage to Veblen (1899), this is a well researched area, particularly in the fashion industry (Belk, Bahn \& Mayer, 1982; Freitas, Kaiser, Chandler, Hall, Kim, \& Hammidi, 2007). In the automotive industry, numerous studies support product-personality congruence and perceived status attached to car ownership (Doob \& Gross, 1968; Solomon \& Herman, 1977; Birdwell, 1968; Grubb \& Stern, 1971; Heath \& Scott, 1998).

Considerable empirical evidence exists that products not only possess personalities with which people may seek congruence, they also possess status enhancing attributes. While the evidence is impressive, it nonetheless displays a fundamental weakness: the research focus has been exclusively upon the product per se, and the qualities it exhibits. Yet merely establishing product qualities/status does not demonstrate an association or transfer of these qualities/status to a product owner or user. This would require empirical evidence of a shift in perceptions of the owner by association with that product.

The only empirical demonstration of any such shift comes from the field of environmental psychology. The focus was on the environment - the room - rather than on products. Canter, West \& Wools (1974) found that a person was perceived differently according to the type of room in which they were found. Using photographs of rooms with the same occupant superimposed within, the characteristics of the room were transferred to the occupant. This became known as the Room Effect. Earlier, Maslow and Mintz (1956) observed a similar Room Effect, whereby the characteristics of a room impacted upon the judgements of people's faces associated with that room. Thus, faces in a "beautiful" room were judged higher in "energy" and "wellbeing" than those in an "average" room, which in turn were judged higher in energy than those in an "ugly" room. In a less direct demonstration, Campbell (1979) found an association between the design of a professor's room and the presumed characteristics of the professor who would be found there. The first two demonstrate direct influence, particularly Canter et al. (1974). The present study sought to demonstrate a similar influence using products. The research question was posed: does the product (in this case, a car) exert an influence upon perceptions of the person associated with it, as does a room? In other words: is there a Product Effect with a measurable influence?

\section{Method}

We adopted and extended the method of Canter et al. (1974). Digital simulations of 'owners' were positioned alongside 'their car', and such extraneous variables as position, colour, orientation, texture, and illumination were digitally standardized. Owners were represented in near identical profiles and without ornamentation (eg: glasses, jewellery) that could influence responses. Considerable effort went into finding owners who were similar in age, attractiveness, and demeanour; for example, a smiling 'owner' could introduce response bias.

Three types of measure were used to identify if a shift in perception of the owner occurred when associated with their car. The first involved perceptions of the physical characteristics of age, height and weight, the second social characteristics of income, employment and education, and the third personality characteristics. The latter employed scales from the Five-Factor Model of personality representing the dimensions of Agreeableness, Extraversion, Conscientiousness, Neuroticism, and Openness to Experience. The Five-Factor Model, developed by McCrae and Costa (1985) - though its origin dates back to Fiske (1949) - has been used extensively, and provides a reliable instrument for investigating personality structure (Digman, 1990). It has been tested using members of diverse cultures: the Philippines (Church and Katigbak, 2002), Zimbabwe (Piedmont, 2002), Turkey (Gülgoz, 2002), Malaysia (Mastor, Putai, \& Cooper, 2000), Australia (McCormack \& Mellor, 2003), Russia (Hřebíčková, Urbánek, Cermák, Szarota, Ficková, \& Orlická, 2002), and with Vietnamese-Americans (Leininger, 2002). 


\section{Procedure}

\subsection{Subjects}

The survey was located on the tutorials page of the Swinburne University of Technology, Faculty of Design website. The page provides free access to tutorials for design programs such as Adobe Flash, Maya, Adobe Photoshop, and Adobe Illustrator.

Upon engaging the web site, a pop-up window gave the option of participating in the survey. If agreed, then one version of the survey stimuli and the questionnaire appeared. Upon completion, respondents were directed to the free tutorials. As an incentive to participate, an $8 \mathrm{~GB}$ iPod touch was offered as a prize.

A total of 1,053 respondents participated in the study; demographic details are provided in Table 1.

Table 1. Background characteristics of subjects - various countries

\begin{tabular}{lll}
\hline Category & Total number & Percentage of total \\
\hline Male & 818 & $78 \%$ \\
Female & 235 & $22 \%$ \\
Age & & \\
$<20$ (years old) & 111 & $11 \%$ \\
$20-29$ & 522 & $49 \%$ \\
$30-39$ & 251 & $24 \%$ \\
$40-49$ & 111 & $11 \%$ \\
$50-59$ & 36 & $3 \%$ \\
$>60$ & 22 & $2 \%$ \\
Country Demographic & & \\
Australia & - & $17 \%$ \\
India & - & $15 \%$ \\
USA & - & $15 \%$ \\
United Kingdom & - & $7 \%$ \\
Singapore & - & $4 \%$ \\
Brazil & - & $4 \%$ \\
Canada & - & $3 \%$ \\
Mexico & - & $2 \%$ \\
Netherlands & - & $2 \%$ \\
Malaysia & - & $2 \%$ \\
other & - & $29 \%$ \\
\hline
\end{tabular}

3.2 Stimuli

Stimuli pictures used similar images of an 'owner' located in the foreground together with images of 'his/her car' in the background. The owners were positioned identically in relation to the vehicle, and the vehicle was digitally modified to be as similar in size, orientation, and colour as possible. Due to the online survey delivery mode, it was expected that respondents would be located in numerous countries. However, it was anticipated that a large proportion would come from Western and Asian countries. For this reason, Caucasian and Asian models were selected to be the owners featured in the survey.

The two cars selected as stimuli were the Mercedes-Benz C-Class and the Proton Persona. Using such extremely dissimilar cars was intentional: if a Product Effect did not manifest for them, it would be unlikely to manifest for more similar cars. The eight stimuli are shown in Figure 1. 


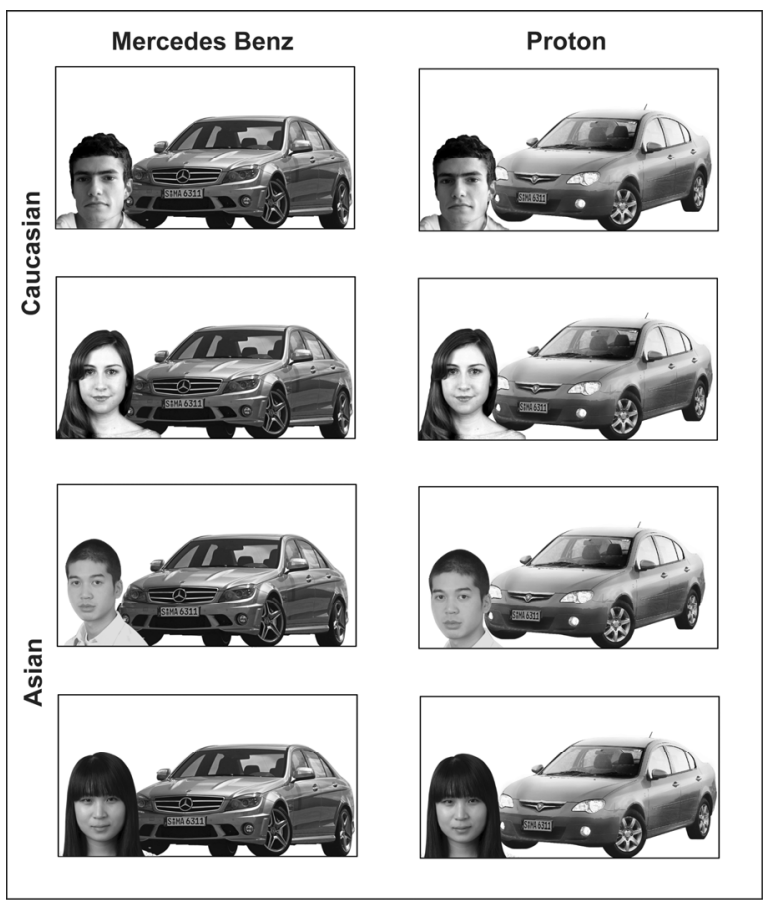

Figure 1. Digitally rendered stimuli images

\subsection{Questionnaire}

The questionnaire had three dimensions: respondents were asked to rate statements about physical, social, and personality characteristics using a nine-point Likert scale indicating agreement or disagreement (from 'strongly agree' to 'strongly disagree'). After pilot tests were conducted in Australia $(n=68)$ and Malaysia $(n=80)$ using the same stimuli and an expanded list of statement scales, it was decided that a number of scales should be excluded from the online survey used here, as these showed no discriminatory influence within the Factor Analyses conducted. Those excluded were: unstable (neuroticism), anxious (neuroticism), vulnerable (neuroticism), friendly (agreeableness), kind (agreeableness), sporty (extraversion), and openness to new ideas (openness to experience). Table 2 lists the scales that were retained for the online survey.

Table 2. Pattern matrix

\begin{tabular}{llc}
\hline Quality & \multicolumn{3}{c}{ Factor } \\
\hline \\
Reliable & .783 & $\underline{2}$ \\
Generous & .762 & \\
Elegant & .761 & \\
Trustworthy & .749 & \\
Efficient & .739 & \\
Stylish & .709 & \\
Organised & .701 & -.101 \\
Attractive & .696 & .107 \\
Creative & .657 & .798 \\
Positive attitude & .600 & .780 \\
Masculine/Feminine & .586 & \\
Height & & \\
Weight & & \\
\hline
\end{tabular}

\section{Results}

Factor Analysis was performed to establish the underlying relationships amongst the scales using Principal Axis Factoring with Direct Oblimin rotation. Kaiser-Meyer-Olkin was .896 and Bartlett's Test of Sphericity achieved a level of $<.001$ indicating a good correlation amongst the scales. Two factors emerged that accounted for $52 \%$ of 
the variance: Factor 1: $42.44 \%$ and Factor 2: 9.75\%. Scales with values greater than .5 were included in the factor. The two factors comprised 11 and 2 variables respectively. Factor 1 was labelled Personality and Factor 2 Physical Attributes.

High Cronbach's Alpha coefficients of .914 and .916 were achieved for the factors of Personality and Physical Attributes respectively. Tests for Skewness and Kurtosis showed that an acceptable normal distribution was attained.

As Factor Analysis reduced the thirteen scales to two factors, Personality and Physical Attributes, two composite scales representing each factor were then used in an ANOVA, along with age, education, and annual income as dependent variables. Three between-subjects independent variables were employed: car (Mercedes-Benz/Proton), owner gender (male/female), and owner nationality (Asian/Caucasian). Table 3 shows the significant main effects and interactions obtained.

Table 3. ANOVA result: significant effects and interactions

\begin{tabular}{|c|c|c|c|c|c|}
\hline Factors & Personality & Physical Attributes & Age & Education & Annual Income \\
\hline Main Effects & & & & & \\
\hline Car & & & & & 0.006 \\
\hline Owner Gender & 0.000 & 0.000 & 0.000 & 0.000 & \\
\hline Nationality of Owner & & & 0.045 & & \\
\hline Interactions & & & & & \\
\hline Car x Owner Gender & & & & & \\
\hline Owner Gender x Nationality & & & & & \\
\hline Car x Owner Nationality & & 0.036 & & & 0.003 \\
\hline
\end{tabular}

4.1 Personality

Results for Personality indicate a significant main effect for gender of owner $(F(1,1046)=22.950, p=.000)$. The respondents perceived the females much more positively than the males.

\subsection{Physical Attributes}

For Physical Attributes a highly significant main effect was obtained for gender of owner $(\mathrm{F}(1,1046)=93.247$, $\mathrm{p}=.000)$, and a significant interaction between car and nationality of owner $(\mathrm{F}(1,1046)=4.425, \mathrm{p}=.036)$. Not unnaturally, the respondents judged the males as taller and heavier than the females. However, both male and female Caucasian owners were perceived as taller and heavier with the Mercedes-Benz than with the Proton. There was no car effect for the Asian owners, as shown in Figure 2.

4.3 Age

The results for Age indicate main effects for gender of owner $(\mathrm{F}(1,859)=13.704, \mathrm{p}=.000)$ and nationality of owner $(\mathrm{F}(1,859)=4.022, \mathrm{p}=.045)$. The female owners were perceived as older than the male owners, and the Caucasian owners were perceived as older than the Asian owners.

\section{4 Education}

A significant effect emerged for gender of owner $(F(1,1043)=16.609, p=.000)$, with the female owners perceived as more educated than the male owners.

\subsection{Annual Income}

A significant interaction was obtained between car and nationality of owner $(F(1,1044)=8.708, p=.003)$. Figure 3 shows that the Caucasian owners were seen as having a higher income with the Mercedes-Benz. No differences were obtained for the Asian owners. 


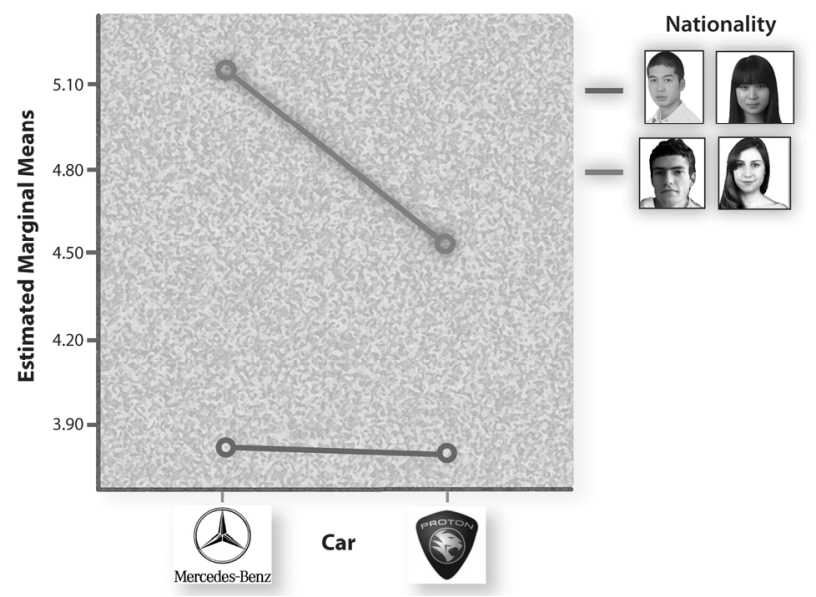

Figure 2. ANOVA results for physical attributes - car and nationality

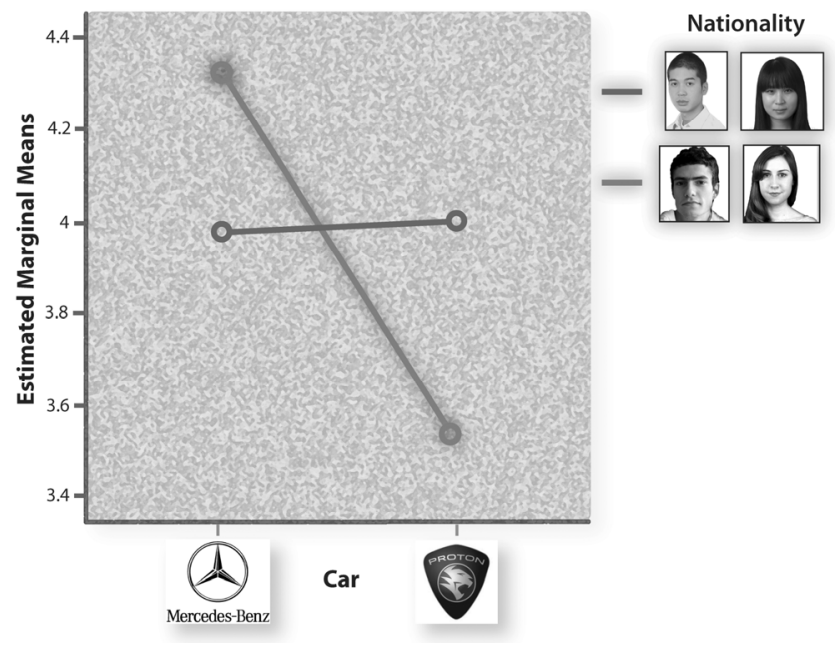

Figure 3. ANOVA results for annual income - car and nationality

\section{The Gender Effect}

An interesting feature of the results is that owner gender exerts a more pervasive influence than car and nationality. The female owners were perceived as higher in personality, age, and education level, irrespective of which car they owned. Within the analysis, gender therefore could be a confounding variable, attracting greater weight and distorting the ANOVA. For this reason, and to unravel this gender effect, it was decided to run separate ANOVAs for each gender. The results are given in Table 4.

Table 4. Univariate ANOVA result, significant effects and interaction

\begin{tabular}{llllll}
\hline Factors & Personality & Physical Attributes & Age & Education & Annual Income \\
\hline Car x Male Caucasian & .002 & .029 & .012 \\
Car x Female Caucasian & & & & .002 \\
\hline
\end{tabular}

5.1 Physical Attributes

There is a significant interaction between car and male Caucasian $(F(1,264)=9.770, p=.002)$, whereby he appears taller and heavier with the Mercedes-Benz than with the Proton (Figure 4). This effect was absent for the Asian male and for the Caucasian and Asian females. 


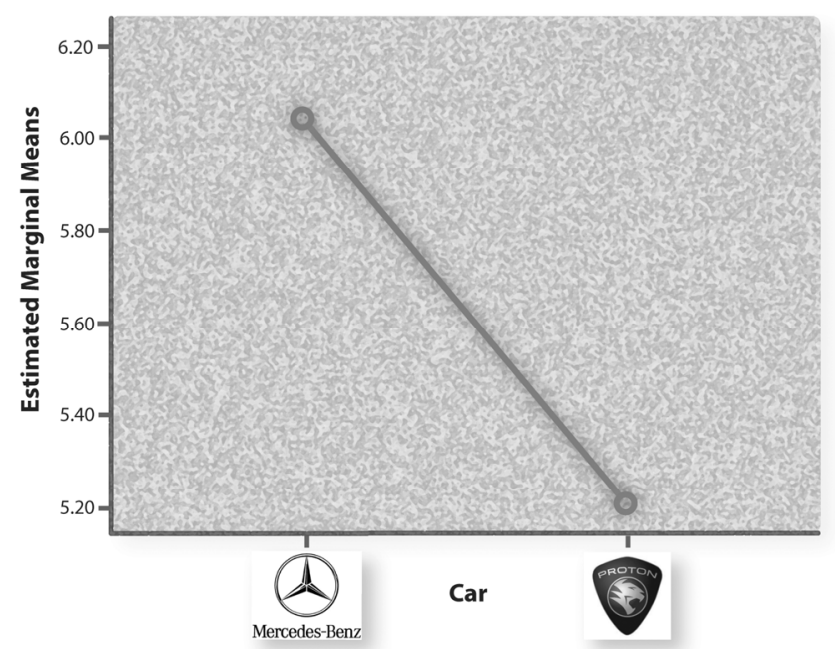

Figure 4. ANOVA results for physical attributes - car/male Caucasian

\subsection{Education}

A significant interaction was obtained between car and male Caucasian owner $(F(1,249)=4.816, p=.029)$, with him being more highly educated with the Mercedes-Benz than with the Proton (Figure 5). This effect was absent for the Asian male and both females.

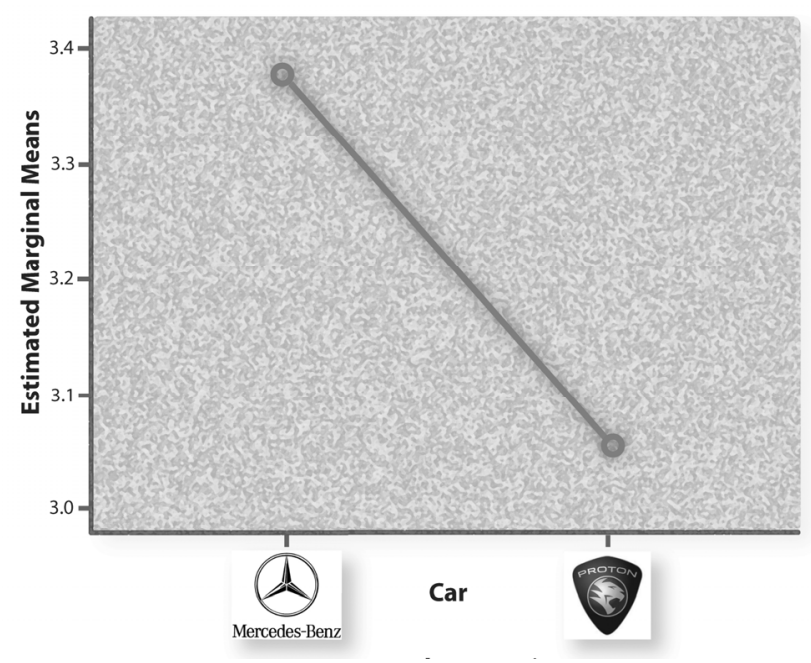

Figure 5. ANOVA results for education - car/male Caucasian

\subsection{Annual Income}

The results indicate a significant interaction between car and Caucasian male owner $(\mathrm{F}(1,249)=6.340, \mathrm{p}=.012)$, and car and Caucasian female owner $(\mathrm{F}(1,2644)=9.770, \mathrm{p}=.002)$. Both Caucasians were perceived as having higher income with the Mercedes-Benz than with the Proton (Figures 6, 7). No effects were obtained for the Asian male or Asian female. 


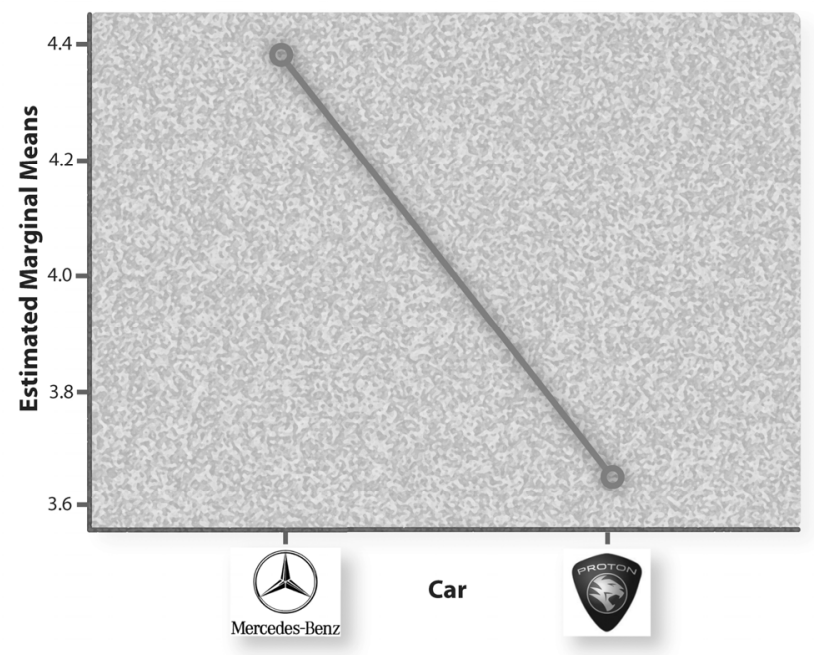

Figure 6. ANOVA results for annual income - car/male Caucasian

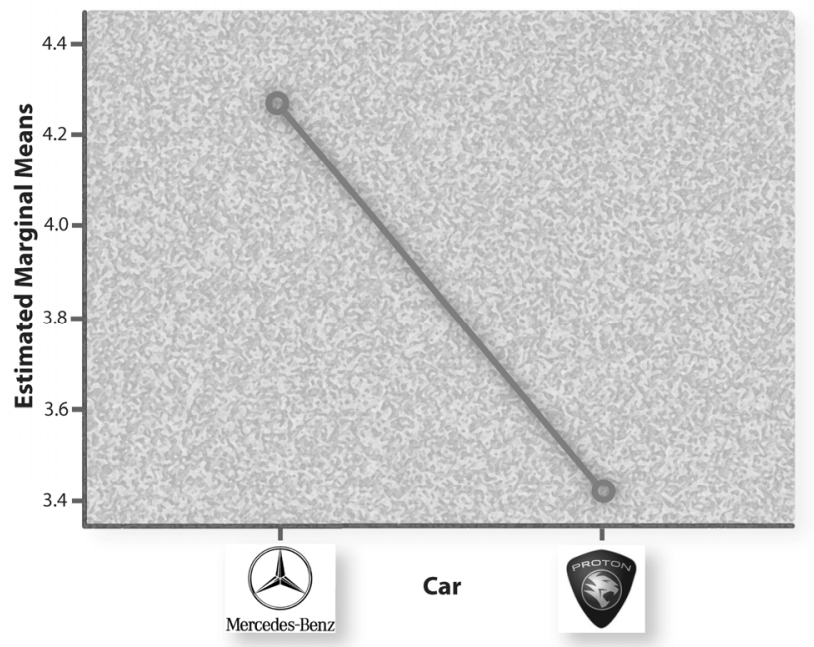

Figure 7. ANOVA results for Annual Income - car/female Caucasian

\section{Discussion}

The results support a transfer of a product's qualities to its owner. These covered physical and socio-economic qualities, ie: height, weight, education, and income. Notably, the transfer did not extend to personality. Furthermore, this transference was highly selective, and impacted mainly upon the male Caucasian owner, and to a lesser extent upon the female Caucasian owner.

The study raises a number of questions. Foremost is the absence of a product/ personality effect. Do products have no effect on how owner personality is perceived? One simple answer is that our results may reflect an absence of personality differences in the two cars featured in the stimuli pictures. Alternatively, it is possible that car personality may not be a 'transferable' quality. While the two cars may differ little in personality, they clearly differ considerably in terms of purchase cost and, by implication, attest to the owners' income-wealth and social standing. Consistent with this, income difference was transferred to both male and female Caucasian owners; and for the male Caucasian extended to differences in height, weight, and education. Effectively, he was taller, heavier, better educated, and more affluent with the Mercedes-Benz than with the Proton. While enhanced affluence would be anticipated, differences in height, weight, and education are less easily accounted for, unless we consider a 'halo' effect whereby one quality gives rise to another. Drawing on another example, Case and Paxson (2006) found that status is inferred by a person's height: if a person is tall, he or she tends to hold higher status employment. By a similar inference, if a person is affluent, then they are likely to be taller, heavier, and better educated - and naturally, increased height would account for increased weight. The results therefore suggest the transference of a cluster of qualities involving status.

While this idea is plausible for the male Caucasian, it does not account for the absence of similar results for the 
female Caucasian. It is noteworthy that all studies into the Room Effect featured males, and not females. Dunn and Searle (2010) are responsible for the only study investigating a product effect that has used both males and females; they found that an expensive car increased the attractiveness of the male driver, but not the female driver. Framed within evolutionary psychology, their results tested and supported the hypothesis that male attractiveness is enhanced by resource capability, as signified by expensive car ownership, but not female attractiveness. Extending this to the present study suggests that the 'halo' effect may be gender-specific. Clearly, the female Caucasian owner appeared more affluent with the Mercedes-Benz, but was it her wealth, her husband's, or her parents'? If not hers, then the other associated attributes, higher education and height/weight, would be unnecessary inferences; whereas for the male, the gender stereotype would favour it being his car.

The suggested answer(s) to the first question gives rise to another. If status was transferred to the male Caucasian owner, why was it not transferred to the male Asian owner? Inevitably, any answer to this is speculative, and may reflect the way cars are internationally advertised and displayed in both print and digital media. A cursory internet search indicates that cars are shown, in nearly all cases, alongside Caucasian owners/drivers. Such practice is not limited to cars, but extends to fashion apparel and homeware. For example, department stores in such culturally dissimilar countries as Malaysia (Islamic) and Vietnam (Communist) are adorned with images of Caucasians wearing jeans, carrying handbags, applying cosmetics, and modelling sportswear. Transference therefore may be more pronounced for Caucasians.

Another question arises: is perceived product transference subject to cultural difference? On one hand, the product itself - in this case, cars - may have different signifier status in different cultures, although the prevalence of such an internationally prestigious brand as Mercedes-Benz, and its concomitant brand image, would argue against this. The cultural origins of the respondents (109 countries represented, with the USA, India, and Australia accounting for $47 \%$ of responses) may more accurately explain why product transference proved more pronounced for the Caucasian images used in the study. Images of Caucasian owners would be familiar to American and Australian respondents, and probably to Indians, but these nationalities may be less familiar with images of Malaysian owners. Perhaps Indian respondents would have identified with Indian owners more readily. Perhaps Vietnamese and Chinese would respond better to their own nationalities of owners.

The above are legitimate questions. In defence of the present study, it focused simply upon the question of whether a Product Effect could be demonstrated. The outcome is affirmative, although the results were unexpected, and consequently indicate avenues that further research would need to examine, in particular regarding the influence of gender, nationality/culture, and product type on the effect elicited. However, along with the Room Effect, there exists a Product Effect. This accords with the wisdom of popular culture, and may explain the Caucasian male in mid-life crisis and his Porsche. Does he look cool, successful, and six years younger? Perhaps he does.

\section{References}

Belk, R. W., Bahn, K. D., \& Mayer, R. N. (1982). Developmental recognition of consumption symbolism. Journal of Consumer Research, 9, 4-17. http://dx.doi.org/10.1086/208892

Birdwell, A. E. (1968). A study of the influence of image congruence on consumer choice. Journal of Business, 41, 76-88. http://dx.doi.org/10.1086/295047

Borkenau, P., \& Liebler, A. (1995). Observable attributes as manifestations and cues of personality and intelligence. Journal of Personality, 63, 1-25. http://dx.doi.org/10.1111/j.1467-6494.1995.tb00799.x

Brunel, F. F., \& Kumar, R. (2007). Design and the big five: linking visual product aesthetics to product personality. Advances in Consumer Research, 34, 238-239.

Campbell, D. E. (1979). Interior office design and visitor response. Journal of Applied Psychology, 64, 648-653. http://dx.doi.org/10.1037/0021-9010.64.6.648

Canter, D., West, S., \& Wools, R. (1974). Judgements of people and their rooms. Journal of Social and Clinical Psychology, 13, 113-118. http://dx.doi.org/10.1037/0021-9010.64.6.648

Case, A., \& Paxson, C. (2006). Stature and status: height, ability, and labor market outcomes. NBER Working Paper Series, 1246, 1-53.

Church, A. T., \& Katigbak, M. S. (2002). The Five-Factor Model in the Philippines: Investigating trait structure and levels across cultures. In R. R. McCrae, \& J. Allik (Eds.), The Five-Factor Model of Personality Across Cultures. New York: Kluwer Academic/Plenum Publishers.

Digman, J. M. (1990). Personality structure: emergence of the five-factor model. Annual Review of Psychology, 
41, 417-440. http://dx.doi.org/10.1146/annurev.ps.41.020190.002221

Doob, A. N., \& Gross, A. E. (1968). Status of frustrator as an inhibitor of horn-honking responses. Journal of Social Psychology, 76, 482-485. http://dx.doi.org/10.1080/00224545.1968.9933615

Dunn, M. J., \& R., S. (2010). Effect of manipulated prestige-car ownership on both sex attractiveness ratings. The British Journal of Psychology, 101, 69-80. http://dx.doi.org/10.1348/000712609X417319

Fiske, D. (1949). Consistency of the factorial structures of personality ratings from different sources. The Journal of Abnormal and Social Psychology, 44, 329-344. http://dx.doi.org/10.1037/h0057198

Freitas, A., Kaiser, S., Chandler, J., Hall, C., Kim, J.-W., \& Hammidi, T. (2007). Appearance management as border construction: least favourite clothing, group distancing and identity ... not! Sociological Inquiry, 67, 323-335. http://dx.doi.org/10.1111/j.1475-682X.1997.tb01099.x

Goffman, E. (1959). The presentation of self in everyday life. New York: Anchor.

Govers, P. C. M. (2004). Product personality. Unpublished doctoral dissertation, TU Delft. Delft, the Netherlands.

Govers, P. C. M., \& Mugge, R. (2004). 'I love my Jeep, because it's tough like me', the effect of product-personality congruence on product attachment. In Kurtgözü, A. (Ed.), Proceedings of the Fourth International Conference on Design and Emotion (pp. 1-15). Ankara, Turkey.

Govers, P. C. M., \& Schoormans, J. P. L. (2005). Product personality and its influence on consumer preference. Journal of Consumer Marketing, 22, 189-197. http://dx.doi.org/10.1108/07363760510605308

Grubb, E. L., \& Grathwohl, H. L. (1967). Consumer self-concept, symbolism and market behavior: A theortical approach. Journal of Marketing, 31(4, Part 1), 22-27. http://dx.doi.org/10.2307/1249461

Grubb, E. L., \& Stern, B. L. (1971). Self-concept and significant others. Journal of Marketing Research, 8 , 382-385. http://dx.doi.org/10.2307/3149582

Gülgoz, S. (2002). Five-factor model and the NEO-PI-R in Turkey. In R. R. Mc Crae, \& J. Allik (Eds.), The five-factor model of personality across cultures (pp. 348). New York: Kluwer Academic/Plenum Publishers. http://dx.doi.org/10.1007/978-1-4615-0763-5_9

Heath, A. P., \& Scott, D. (1998). The self-concept and image congruence hypothesis: an empirical evaluation in the motor vehicle market. European Journal of Marketing, 32, 1110-1123. http://dx.doi.org/10.1108/03090569810243749

Heffner, R. (2007). Semiotics and Advanced Vehicles: What Hybrid Electric Vehicles (HEVs) Mean and Why it Matters to Consumers, PhD Dissertation, Institute of Transportation Studies, University of California, Davis, Research Report UCD-ITS- RR-07-30.

Hřebíčková, M., Urbánek, T., Cermák, I., Szarota, P., Ficková, E., \& Orlická, L. (2002). The NEO five-factor inventory in Czech, Polish, and Slovak contexts. In R. R. Mc Crae, \& J. Allik (Eds.), The five-factor model of personality across cultures. New York: Kluwer Academic/Plenum Publishers.

Laumann, E. O., \& House, J. S. (1970). Living room styles and social attributes: the patterning of material artifacts in a modern urban community. Sociology and Social Research, 54, 321-342.

Leininger, A. (2002). Vietnamese-American personality and acculturation: an exploration of relations between personality traits and cultural goals. In R. R. Mc Crae, \& J. Allik (Eds.), The five-factor model of personality across cultures (pp. 197-226). New York: Kluwer Academic/Plenum Publishers. http://dx.doi.org/10.1007/978-1-4615-0763-5_10

Levy, S. J. (1999). Symbols for sale. New York: Sage Publications Inc.

Maslow, A. H., \& Mintz, N. L. (1956). Effects of esthetic surroundings: I. Initial effects of three esthetic conditions upon perceiving 'energy' and 'well-being' in faces. Journal of Psychology: Interdisciplinary and Applied, 41, 247-254. http://dx.doi.org/10.1080/00223980.1956.9713000

Mastor, K. A., Putai, J., \& Cooper, M. (2000). Malay culture and personality: a big five perspective. American Behavioral Scientist, 44, 95-111. http://dx.doi.org/10.1177/00027640021956116

McCormack, L., \& Mellor, D. (2002). The role of personality in leadership: an application of the five-factor model in the Australian military. Military psychology, 14, 179-197. http://dx.doi.org/10.1207/S15327876MP1403_1 
McCrae, R. R., \& Costa Jr., P. T. (1992). Discriminant validity of NEO-PIR facet scales. Educational and Psychological Measurement, 52, 229-237. http://dx.doi.org/10.1177/001316449205200128

Montepare, J. M., \& Zebrowitz-McArthur, L. (1988). Impressions of people created by age-related qualities of their gaits. Journal of Personality and Social Psychology, 55, 547-556. http://dx.doi.org/10.1037/0022-3514.55.4.547

Munson, J. M., \& Spivey, W. A. (1980). Assessing self concept. Advances in Consumer Research, 7, 598-603.

Piedmont, R. L., Bain, E., McCrae, R. R., \& Costa, P. T. (2002). The applicability of the five- factor model in Sub-Saharan Culture: the NEO-PI-R in Shona. In R. R. Mc Crae, \& J. Allik (Eds.), The five-factor model of personality across cultures (pp. 155-174). New York: Kluwer Academic/Plenum Publishers. http://dx.doi.org/10.1007/978-1-4615-0763-5_8

Solomon, H., \& Herman, L. (1977). Status symbols and prosocial behaviour: the effect of the victim's car on helping. Journal of Psychology: Interdisciplinary and Applied, 97, 271-273. http://dx.doi.org/10.1080/00223980.1977.9923973

Van Kesteren, I., Stappers, P., \& Kandachar, P. (2009). Representing product personality in relation to materials in a product design problem. Nordic Design Research Conferences. Retrieved from http://ocs.sfu.ca/nordes/index.php/nordes/2005/paper/view/107

Veblen, T. (1899). The Theory of the Leisure Class: An Economic Study of Institutions. New York: The Macmillan Company. 